The Orang-sakays are very kind to their women and daughter:, who can even inherit the title of Pateu. Their wedding customs contain survival of the cuttom of stealing brides. On a day agreed to before, the bride, in presence of ber parents and friends, runs away to the forests, and the bridegroom, who follows her after some time, must find her during a fixed lapse of time. If she does not wish to marry him she can always conceal herself in the wo ods so as not to be found. They have maintained also the communal marriage, that is, the wife passes from one man to another for a certain time. They are much afraid of death, and if a member of the community becomes seriously ill, they abandon him in the forest with a supply of food, and leave their buts for ever.

In his fourth lecture, M. Miklukho-Maclay gave an account of his cruise among the i-lands of the Malayan Archipelago, at the islands of Micronesia and Melanesia, as well as of his work in Australia. The anthropological researches in the Malayan archipelago were far more successful than in Melanesia or New Guinea. He had no longer to deal with wild tribes, and the schools, hospitals, and prisons maintained by the Dutch on

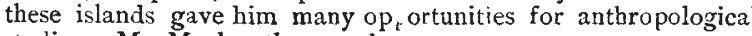
studies. M. Maclay thus made very numerous measurements and photographs of Malayans, which will afford the necessary materials for comparing them with other allied races.

In 1876 , when going for a second time to the Maclay coast of New Guinea, the indefatigable traveller had an opportunity of visiting the islands of Western Micronesia. He found there that the Micronesian race is very nearly akin to the Polynesian; but still, be thinks it is most probable that it contains a mixture of Melanesian blood, which appears, especially in the more curly hair ; in several instances (on the Pelan Islands), the hairs were purely Melanesian, and the darkness of the skin and several distinctive features of the skull showed unmistakable traces of mixture with Melanesians. On the Lub, or Hermit Islands, M. Maclay found a mixture of Melanesians with Micronesians, and on the next group of islands, Escheker, or Eschikie, he discovered the true border-line of the straight-haired Micronesian race. The most important results of this jurney were published in the Sitzungsberichte der Berlinır Gesellschaft für Anthropologie, \&c., meeting of March 3,1878 .

In 1879 M. Maclay left Sydney on board an American schooner for a cruise among the islands of Melanesia. He visited New Caledonia, and journeyed in the interior of it, the Loyalty Islands, and many islands of the New Hebrides, making everywhere anthropological measurements and drawings. Many inhabitants of the New Hebrides proved to be brachiocephalic. Thence be proceeded to the Santa Cruz Islands (where Commodore Goodenough, several sailors, and Bishop Paterson were killed by poisoned arrows), and made measurements of those natives who came on board the schooner. Reaching then the Admiralty Islands, he stayed there for two months, and was enabled to complete to a great extent the observations of the Challenger expedition. Visiting further the Lub or Hermit islands, which are said to have been peopled by a few natives landed in a canoe from the Admiralty Islands, and where the Melanesians are continually crossed with Micronesians, as the inhabitants bring every year slaves and women from the Ninigo group-M. Maclay proceeded to the Trobrian group of islands which are very rarely $v$ sited by Europeans, and thence to the Solomon and the Luisiadea Islands. The journey lasted for 409 days, out of which 237 were spent on shore. The results were as numerous as important, the chief of them being that brachiocephaly is far more usual in Melanesia than it was before ; indexes measuring $8 \mathrm{r}$, and even 85 , being not rare. Further results of this journey were published in the Izvestia of the Russian Geographical Society for 188r, and in a letter to Prof. Virchow, which appeared in the Sitzungsberichte of the Berlin Society of Anthropology.

M. Miklukho-Maclay concluded his journey by landing at Somerset, on the northern extremity of Australia, and at several places of the eastern coast, in order to make acquaintance with the black Australian race. It is known that several opinions are current as to the origin of this race. Some anthropologists consider them as Papuans, while others consider them as Polynesians, and Prof. Huxley has made of them an independent race of Astraloids. As far as M. Maclay's observations go, he is inclined to consider them, like Huxley, as a race sui generis. But he intends to return again to Australia in order further to study this question.

When staying at Brisbane, M. Maclay undertook an excursion into the interior of the country to see if there really exists an "unhaired" race, of which he was told in Europe. Close by Saint George's Town, on the Ballon River, he discovered a few members of one family who really were representatives of the Atrychia universalis; they had only a dozen bairs on their eyelids, and said that they were already a third generation of unhaired people. More details of this occurrence of atrychia, together with observations on inherited hypertrichosis (hairs coverin ? all the body and face) were given by M. Maclay in a letter to Prof. Virchow which appeared in the Verhandlungen of the Berlin Anthropological Society for $188 \mathrm{r}$, as well as several other papers on Australians ("Ueber die Mika Operation in Central Australien ; Langbeinigkeit der australischen Franen," \&c.).

At Brisbane M. Maclay had at his disposal very rich anthropological material for the study of the comparative anatomy of the brain of the Australian, Melanesian, Malayan, and Mongolian races, as the authorities had given him all facilities for having fresh brains of representatives of all these races who died in the hospitals of the port, or were executed. The Survey Office of Brisbane offered him the use of its excellent photographs, which rendered him very great services. This rich material, left mostly at Sydney, has $n$ t t yet been worked out by M. Maclay; but he can already state that the brains of different races afford substantial differences in the development of the corpus callosum, the pons varolii, and the cerebellum, as well as in the relative development of nerves and in the grouping of the sinuosities of the great brain.

Further interesting studies in comparative anatomy were made by M. Maclay on the brains of Marsupials, as well as of the Ornithorhynchus, the Echidna, and others. The chief occupation of M. Maclay in Australia being thus comparative anatomy, he proposed to the Linnean Society of New South Wales to open a biological station where everybcdy could "undisturbed and undisturbing" carry on biological and anatomical studies. The success which has met his proposal our readers already know of. The recently-founded "Australian Biological Association" will take care of the new station.

The Geographical Society not having at its disposal the necessary sums for publishing the scientific work which $M$. Maclay proposes to publish, the Emperor has allowed the sum of $2200 l$. for covering the expenses of the publication.

\section{THE RECENT AND COMING TOTAL SOLAR ECLIPSES ${ }^{\mathrm{I}}$}

THE following note has been drawn up in anticipation of the detailed accoun's of the work done by me in Egypt on the eclipsed sun of $\mathrm{I} 882$, May $\mathrm{I} 7$, which $\mathrm{I}$ am reparing to lay before the Royal Society, because as the next total eclipse occurs next May, there is no time to be lost if any attempt is to be made to secure observations, and I am of opinion that such observations are most important.

I have prefaced the statement of the work done by a reference to the considerations which led me to undertake it, and I have added a scheme of observations which, in the present state of our knowledge is, I think, most likely to produce results of value.

I. In order to understand the recent change of front in solar research which has followed the introduction of the view of the possible dissociation of elementary bodies at solar temperatures, and suggested the later laboratory, and especially the later eclipse observations with which we are now chiefly concerned, we must first consider what facts we may expect on the two hypotheses. In this way we can see which hypothesis fits the facts best, an 1 whether there are any inquiries possible during eclipses of a nature to throw light on the question.

2. On the old hypothesis the construction of the solar atmosphere was imaged as follows :-

(I.) We have terrestrial elements in the sun's atmosphere.

(2.) They thin out in the order of vapour den ity, all being represented in the lower strata, since the solar atmosphere at the lower levels is incompetent to dissociate them.

(3.) In the lower strata we have especially those of higher atomic weight, all together forming a so-called "reversing layer" by which chiefly the Fraunhofer spectrum is produced.

3. The new hypothesis necessitates a radical change in the above views. According to it the three main statements made in paragraph 2 require to be changed as follows :-

I Paper read at the Royal Society, Nov. 23, by J. Norman Lockyer,
F.R S 
(I.) If the terrestrial elements exist at 'all in the sun's atmosphere they are in process of ultimate formation in the cooler parts of it.

(2.) The sun's atmosphere is not composed of strata which thin out, all substances being represented at the bottom ; but of true strata like the skins of an onion, each different in composition from the one either above or below. Thus, taking the sun in a state of quiescence and dealing only with a section, we shall have as shown in (Fig. I) $C$ say containing neither $D$ nor $B$, and $B$ containing neither $A$ nor $C$.

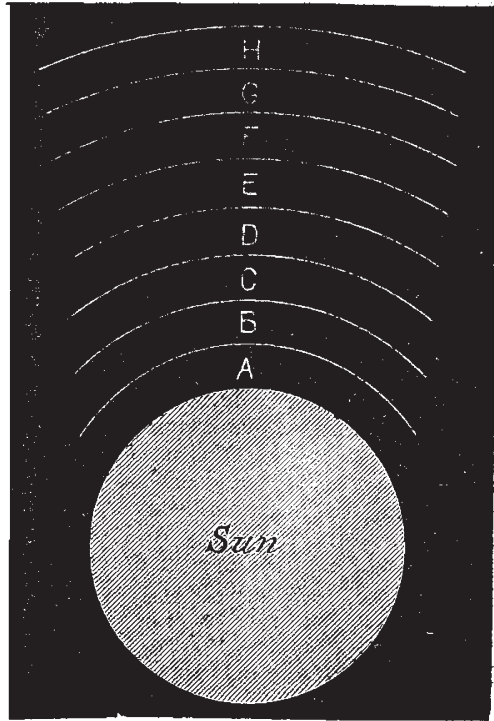

FIG. $x_{0}$

(3.) In the lower strata we have not elementary substances of high atomic weight, but those constituents of all the elementary bodies which can resist the greater heat of these regions.

4. The conditions under which we observe the phenomena of the sun's atmosphere have not, as a rule, been sufficie thy borne in mind, and it is quite possible that the notion of the strata thinning out has, to a certain extent, been based more upon the actual phenomena than upon reasoning upon the phenomena.

5. Take three concentric envelopes of the sun's atmosphere,

6. Now take three concentric envelopes, A, B, C, so that only A rests on the photosphere. The phenomena will in the main be the same as in the former case, i.e. the line $\mathrm{C}$ will still appear to rest on the spectrum of the photosphere, for it will be fed, so to speak, fron $C^{\prime}$ and $C^{\prime \prime}$, though absent along the line $\mathrm{CB} A$ at $\mathrm{B}$ and $\mathrm{A}$.

7. Thus much having been premised with regard to the observations as conditi med by the fact that we are observing a sphere, we can now proceed to note how the two hypotheses deal with the facts.

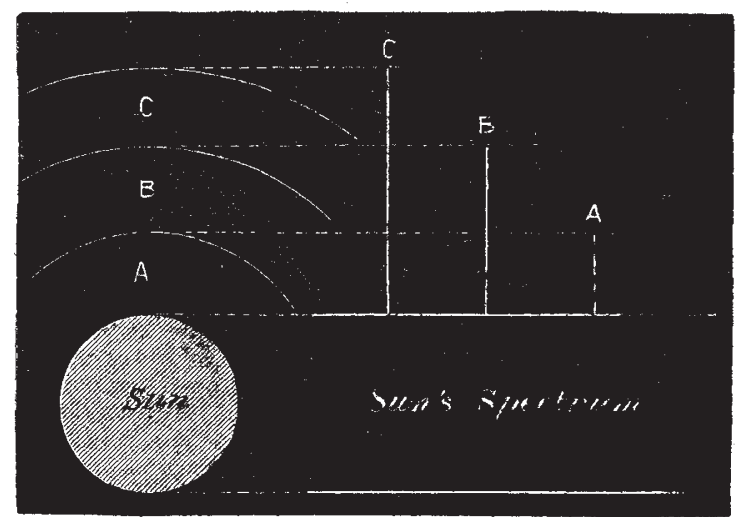

FIG. 2.

Old Hypothesis.

I. The spectrum of each elenent as seen in our laboratories should be exactly represented in the solar spectrum.

FACT, - There is a very wide difference between the spectra.

2. Motion in the iron vapour, e.g. in a spot or a prominence, should be indicated by the contortion of all the iron lines equally.
Motion should be unequaily indicated because the lines are due to divers constituents which exist in different strata according as they can resist the higher temperatures of the interior regions.

FACT. - The indications show both rest and motion.

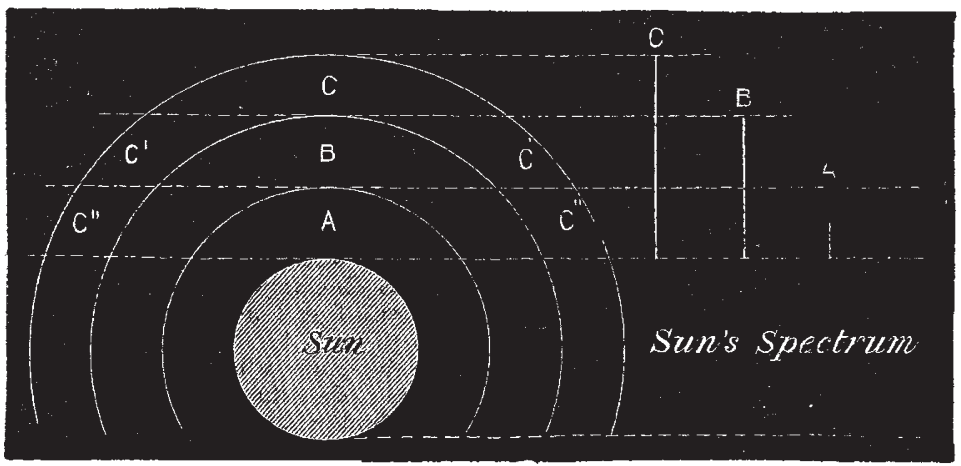

FIG. 3.

$\mathrm{A}, \mathrm{B}, \mathrm{C}$, so that $\mathrm{C}$ extends to the base of $\mathrm{A}$, and $\mathrm{B}$ also to the base of A, that ic, in both cases to the photosphere. Then, whether we deal either with the sphere or a section of it, the lengths of the lines in the spectru'n of the strata C, B, A will give the heights to which the strata extend from the sun, and show whether $B$ and $A$ respectively thin out. As the material is by hypothesis continuous down to the sun, the lines will be continuous down to the spectrum of the sun seen bolow as shown.
3. The spectrum of iron in a prominence should be the same as the spectrum of iron in a sun-spot.

FACT, - The spectra are as
The spectrum of iron in a prominence should be vastly different from the spectrum of iron in a sun-spot, because a spot is cooler than a prominence.

s dissimilar as those of any two elements. 


\section{Old Hypothesis}

4. The spectra of spots and prominences should not vary with the sun-spot period.

\section{FACr.-They do vary.}

5. The spectrum of the base of the solar atmosphere should most resemble the ordinary Fraunhofer spectrum. maximum.
New Hypothesis

The spectra should vary because the sun is hotter at

The spectrim of the base should least resemble the Fraunhofer spectrum, because at the base we only get those molecules which can resist the highest temperatures.

FACr.-As a rule the lines seen at the base are either faint Fraunhofer lines, or are entirely absent from the ordinary spectrum of the sun.

6. Qua the same element the lines widest in spots should always be the same

FACT.-There is immense variation.

$Q u \hat{\alpha}$ the same element the Jines widest in spots should vary enormously, because the absorbing material is likely to originate in and to be carried to different depths.

7. The spectra of prominences should consist of lines familiar to $u_{s}$ in our labora. tories, because solar and terres. trial elements are the same.

The spectra of prominences should be in most cases unfamiliar, because prominences represent outpourings from a body hot enough to prevent the coming together of the atoms of which our chemical element are composed.

FACT.-When we leave $\mathrm{H}, \mathrm{Mg}, \mathrm{Ca}$, and $\mathrm{Na}$, most of the lines are ei her of unknown origin or are feeble lines in the spectra of known elements.

8. From the above sketch, hasty though it be, it is, I think, easy to gather that the new view includes the facts much better than the old one, and in truth demands phenomena and simply and sufficiently explains them, which were stumbling blocks and paradoxes on the old one.

This being so, then, it is permissible to consider it further.

9. Let us first suppose, to take the simplest case, that the sun when cold will be a solid mass of one pure element, i.e. that the evolution brought about by reduction of temperatures shall be along one line only. Let us take iron as the final product.
(3.) We shall rarely, if ever, see the darkest lines affected in spots and prominences.

(4.) The germs of iron are distributed among the various strata according to their heat-resisting properties, the most complex at $\mathrm{I}$, the least complex at A.

(5.) Whatever process of evolution be imagined, as the temperature runs down from $A$ to $L$, whether $A, 2 A, 4 A$; or $A+$

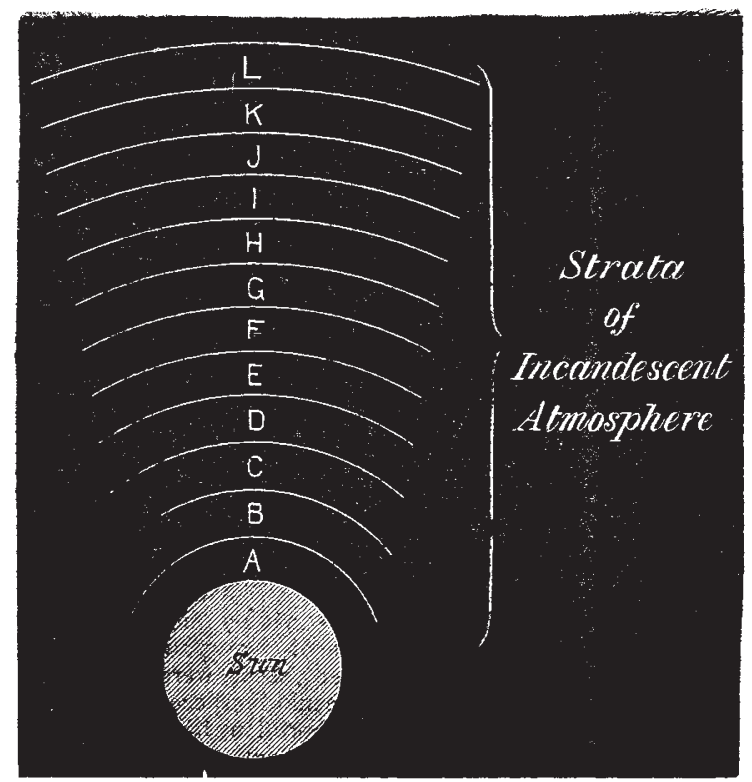

Fig. 4.

$\mathrm{B}, 2[2(\mathrm{~A}+\mathrm{B})]$, or $\mathrm{X}+\mathrm{Y}+\mathrm{Z}$, the formed material or final product is the work of the successive associations rendered possible by the gradually lowering temperature of the successive strata, and can therefore only exist at $\mathrm{L}$.

Io. Now at this point a very important consideration comes

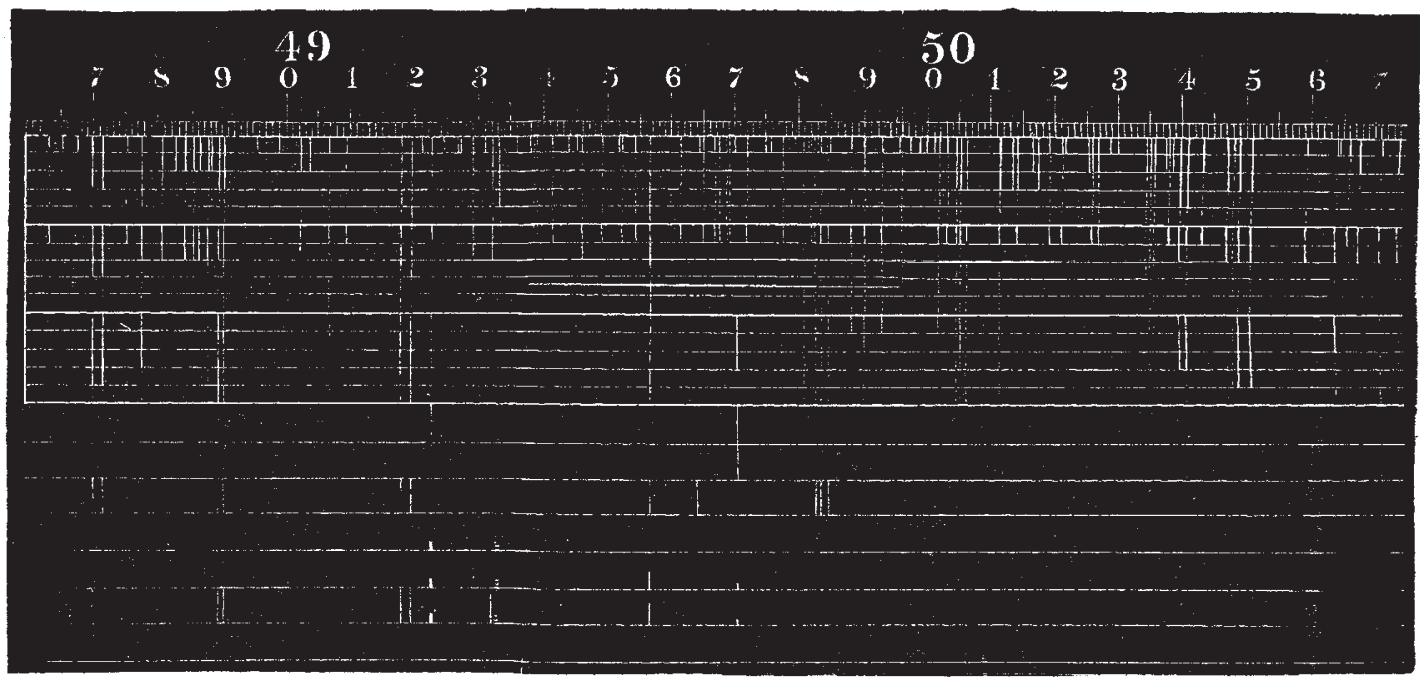

FIG. 5 .

Then the sun's atmosphere on the new theory quâ this one in. It was stated (in 6) while discussing the cunditions of obserelement may be represented as follows :-

Assume strata A-L. Then-

(I.) The Fraunhofer spectrum will integrate for us the absorption of all strata from $A$ to $L$.

(2.) The darkest lines of the Fraunhofer spectrum will be th se absorbed nearest the outside of the atmosphere. vation, that whether we were dealing with strata of substance extending down to the sun or limited to certain heights, the spectral lines would always appear to rest on the solar spectrum, and that the phenomena would in the main be the same

I1. This, however, is true in the main only, there mnst be a difference, and this suppiies us with a test between the rival 
hypotheses of the greatest stringency. The stratum $B$, being further removed from the photosphere tban the stratum $\mathrm{A}$, will be cooler, its lines therefore will be dimmer, and the lines of $\mathrm{C}$ will be dimmer than the lines of $\mathrm{B}$, and so on. So if we could really observe the strata, the longer a line is, i.e., the greater the height at which the stratum which gives rise to it lies, the dimmer the line will be.

12. Now our best chance of making such an observation as this is during a total eclipse. We do not see the lines ordinarily in consequence of the illumination of our air. As during an eclipse before totality the intensity of this illumination is rapidly diminishing, the lines first visible should be short and bright, and should remain short while the new lines which become visible as the darkness increases should be of gradually increas. ing length, so that the spectrum should become richer in the way indicated in Fig. 5.

1 3. Further, the lines in $\mathrm{x}$ should be lines seen in prominences, and not in spots, and relatively brighter in the spark than in the arc, while the longer lines added in 2 and 3 should be lines affected in spot:, and not in prominences.

14. All these phenomena were predicted for the Egyptian eclipse a year before its occurrence, and were verified to the letter for the line; of iron over a purposely limited region.

15. The actual observations of the iron lines made at Sohag are shown in the accompanying map, and these actual observations are contrasted with the lines thickened in spots, the lines observed in the prominences by Tacchini, those intensified on passing from the arc to the spark. The Fraunhofer lines are also given according to Angström and Vogel, and the iron spectrum of the arc and spark according to Ângström and Thalén. The observations during the eclipse were made 7 minutes, 3 minutes, and 2 minutes before totality as the air was gradually darkened, by which darkening, succe: sive veils, as it were, were lifred so that the more delicate phenomena could be successively seen.

I6. We begin with one short and brilliant line constantly seen in prominences, never seen in spots. Next, another line appears, also short and brilliant, constantly seen in prominences, and now, for the first time, a longer and thinner line appears, occasionally noted as widened in spots, while last of all we get very long, very delicate relatively, two lines constantly seen widened in spots, and another line not seen in the spark and never yet recorded as widened in the spots.

I7. The procession from the hot to the colder is apparent, and the simplicity of the spectrum as opposed to the Fraunhofer spectrum even yet, is eloquent of the gradual approximation which would be still possible if the darkness could be greater and our attack more complete.

18. It will be noted over what an excessively small range the observations extend. We want similar observations over a wider range during future eclipses, and to do this work properly many observers armed with similar instruments must divide the whole or part of the solar spectrum amongst them, preferably that part between $\mathrm{F}$ and $\mathrm{D}$ which has been most closely watched in prominences and spots by Tacchini and myself.

19. I next pass to anotber point on which an observation was made in Egypt.

20. In Fig. 4 we con-idered the sun's atmosphere, taking the simplest case, that of one element; but evolution and the chemistry of our earth teach us that when the sun cools it will be a very complex ma-s chemically. If the laws of evolution hold we need not expect that this will largely increace the complexity of the hottest layers $A$ and $B$, but higher up, say at $\mathrm{H}-\mathrm{L}$, the complexity of chemical forms produced by evolution along the fittest lines will be very considerable.

2I. These strata $\mathrm{H}-\mathrm{L}$ may be taken to represent the corona. Its spectrum, therefore, should not be a continuous one, but should consist of an integration of all the radiations and absorp. tions of these excessively complex layers.

22. The spectrum of the corona, as I saw it in Egypt exactly answered to this description. Instead of the gradual smooth toning seen, say in the spectrum of the limelight, there were maxima and minima producing an appearance of ribbed structure, the lines of hydrogen and 1474 being, of course, over all. 'This observation, however, requires confirmation, for the look I had at the corona spectrum was instantaneous only.

23. This observation should certainly be repeated during future eclipses with the proper instrumental conditions, i.e. small intensely bright image on narrow slit and spectroscope of small disper:ion. I believe that, under these conditions, photographs could readily be obtained with the new plates.
24. Now an eclipse occurs next May at a critical time of the sun's activity, for, so far as we can see, we shall be nearly at sun-spot maximum, and I hold that it will be a disgrace to our nineteenth century science, if efficient steps are not taken by those who are regarded as the leaders of science in this and other civilised countries to secure adequate observations.

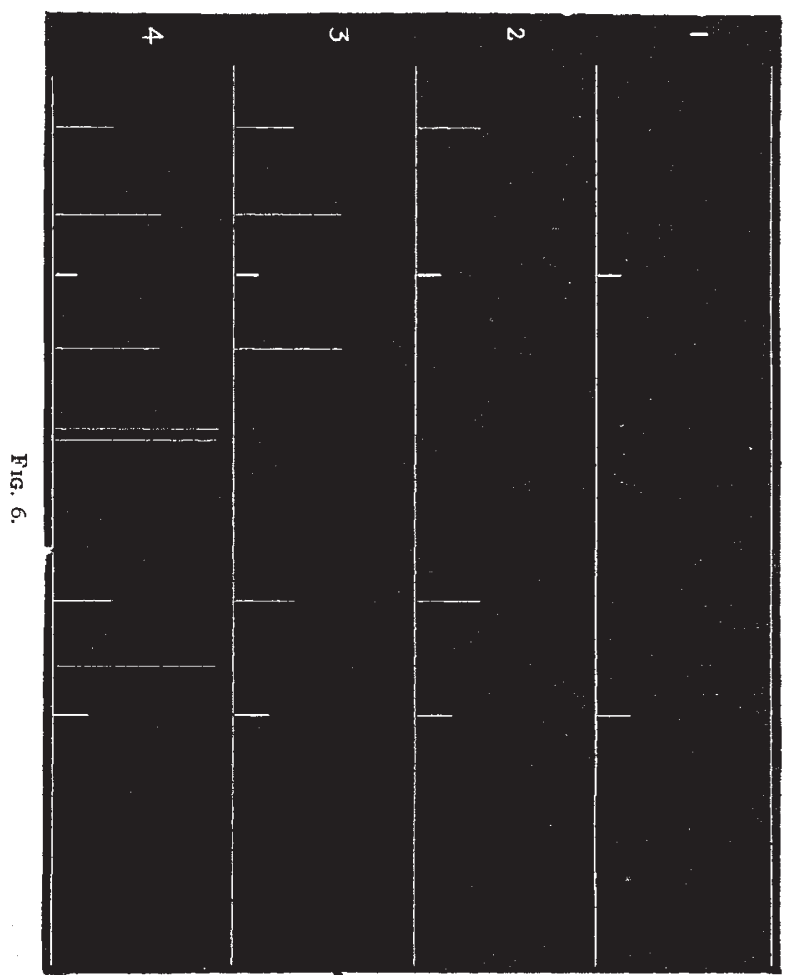

25. So far I have only referred to those special observations undertaken this year to discriminate between two rival hypotheses, but both bypotheses may be wrong in many points, so that we must not limi: ourselves to such observations, but collect facts over the whole field, as has always been the custom in eclipse expeditions.

26. In my opinion the following scheme shows the observations which, in the present state of our knowledge, it is most desirable to secure. The scheme, I am aware, is by no means exhaustive. I give the observations in the order of im. portance I attach to them, having regard to the present position of solar theory and the conditions of eclipse observations.

(I.) 6-inch equatorial of long focu=, perfect clockwork, spectroscope with dispersion of at least five prisms of $60^{\circ}$

Clamp point of disappearance of sun at base of normal slit, and record phenomena observed from ten minutes before totality to actual totality.

a. Order in which lines appear.

$b$. Brightness and length when first visible.

The spectrum from $\lambda 4800$ to $\lambda 5900$ should be distributed among at least nine observers.

Repeat observations after totality on point of reappearance.

(2.) 6-inch photographic lens of 4-feet focus, perfect clock, same dispersion as above.

Clamp point of disappearance of sun on centre of tangential slit and record phenomena observed from ten minutes before totality to actual totality.

$a$. Order in which lines appear.

$b$. Brightness and length when first visible.

Repeat observations after totality on point of reappearance. Same part of spectrum, same distribution as in (I).

(3.) 6-inch photographic lens as in (2).

Photographic phenomena before and after totality on slowly ascending or descending or rotating plate, taking care to expose only narrow strip of plate.

(4.) Ditto. Spectroscope of small dispersion, long slit. 
Photograph spectrum of corona during totality on buth sides of dark moon.

(5.) Prismatic camera, 6-inch photo. lens as in (2), but with grating.

Use first order spectrum on one side and second order on the other.

Commence two minutes before totality. Continue till two minutes after totality on gradually ascending or descending or rotating plate.

(6.) 6-inch photo. lens as in (2), mounted on alt-azimuth. Fine slit. One prism of $60^{\circ}$. To observe spectrum of corona.

(7.) Photographs of corona of short, midium, and very long exposure to determine form and true solar limit of apparent corona due to the illumination of our air, using for the latter purpose the photographic intensity of the image of the moon.

I am aware that because Solar Physics is a new subject, and one so entirely in the domain of pure science, the above scheme may appear ridiculous to many, for if carried cut in its completeness its cost would perhaps amount to the sixtieth part of the sum expended on the Transit of Venus in 1874 . I have, however, felt myself bound to put it forward as an ideal scheme and one which, if several civilised Governments do each a little, concerted action may help us in part to realise. I am informed that the French and Italian Governments are already making preparations for observations, and my desire is that we may be represented on an occasion which, having regard to the duty which is incumbent upon us to secure observations for the use of those who come after us, is one of high importance.

\section{SCIENTIFIC SERIALS}

The American Naturalist, November, I882, contains:-On the ancient man of Calaveras, by W. O. Ayres.-On the grey rabbit, by S. Lockwood--On the genus Nebalia and its fossil allies, representing the order Pbyllocarida, by A. S. Packard, jun.-American work on recent mollusca, 188I, by W. $\mathrm{H}$. Dall. - Progress of invertebrate palæontology in the United States in I88I. by C. A. White.-On the number of bones at present known in the pectoral and pelvic limbs of birds, by R. W. Shufeldt.-The Editor's table-Recent literature.-General notes.

Zeitschrift fur wissenschaftliche Zoologie, Bd. 37, Heft 3, November 1, I882, contains:- On the structure and development of Dinophilus apatris, by Dr. E. Korschelt (plates $2 \mathrm{I}$ and 22). The author would place the forms belonging to this genus in a new family of the Turbellaria. - Studies among the Lampyridæ, by $H$. Ritter v. Wielowiejski (plates 23 and 24 ). - On the deposition of bone in the skeleton of bony fishes, by Max Köstler (plate 25). - On the origin and development of the green cells in Hydra, by Dr. Otto Hamann (plate 26); see remarks on this paper by Prof. Lankester, NATURE, vol, xxvii. p. 87 .

Bulletin de la Soc. Imp. des Naturalistes de Moscou, I882, No. I, contains :-On the geology of the Windimir district, by H. Trautschold.-New lepidoptera of the Amur land, by $\mathrm{H}$. Christoph (conclusion).-OOn the stone-growth of Sarepta-list of the Staphylinidr, and on some new plants of Sarepta, by A. Becker.-On the geographical distribution of the hop in ancient times, by Dr. C. O. Cech. -A protest relative to palæontological nomenclature, by $H$. Trautschold.-Remarks on some anomalies found in the form and colour of the plants in the various countries of the Russian territory, by Dr. A. von Riesenkampff.Note on an instrument to measure the intensity of gravity, by $\mathrm{A}$. Issel.- On crinoids, addenda and corrigenda, by $\mathrm{H}$. Trautschold. - Materials for a fauna of the Black Sea, fasc. iii. Vermes, by V. Czerniavsky. In Russian, but the diagnoses of new genera and species are in Latin.

Revue internationale des Sciences biologiques, October 15, 1882, contains :-Translation of Prof. Pringsheim's "Researches on Chlorophyll."-M. Roujon, on the faculty of speech in mammals.-Prof. Abel, on the dangerous properties of fine coal dust (translation). - M. Viguier, on orientation and its organs in animals and in man.-Proceedings of the Academy of Sciences, Paris.

Rendiconto delle Sessioni dell' Accademia delle Scienze dell' 1stituto di Bologna, I881-82.- We note the following: On the succenturiate spleen of the dog, and on the reproduction of the spleen by pathological processes that have abolished the function of that viscus, by S. Tizzoni.-On adaptation of species to environment; new researches on the genetic history of Trema- todes, by S. Erculani.-On the craniology of lunatics, by S. Peli.-On congenital deviations of the vertebral column in domestic animals, by S. Gotti.- Function of the cœetum and the rest of the large intestine, by S. Vella.-On polydactylia and polymelia in man and vertebrates, by S. Ercolani.-On the variations and the course of the river Po, by S. Predieri.-Meteorology applied to the study of botany, with a description of a new geothermometer, by S. Bertoloni - On some new electric figures, by $\mathrm{S}$. Villari.-On electric shadows, by S. Righi.-On the mirute anatomy of the muscles in insects which move their wings, by S. Ciaccio.-The elevation of the Bolognese Apennines by direct action of gravity and of lateral pressures, by S. Bombieri.-Experimental researches on nerve-stretching, by S. Rossi.

\section{SOCIETIES AND ACADEMIES LONDON}

Royal Society, November 23. - "Monthly Means of the Highest and Lowest Diurnal Temperatures of the Water of the Thames, and Comparison with the corresponding Temperatures of the Air at the Royal Observatory, Greenwich." By Sir George Biddell Airy, K.C.B., F.R.S., late Astronomer Royal.

The observations were instituted at the suggestion of the conductors of the Medical Department in the Office of the Registrar General of Births, Deaths, and Marriages, with the view of supplying some knowledge of an element which may possibly affect the sanitary condition of the metropolis. The plan of observations was arranged at the Royal Observatory of Greenwich; and the instruments were procured and mounted, and repaired when necessary, under the care successively of James Glaisher, Esq., and William Ellis, Esq., superintendents of the Magnetical and Meteorological Department of the Observatory. The self-recording instruments were attached to the hospital ships successively anchored in the Thames, nearly opposite to Greenwich; and their records were read and registered by the medical officers of those ships, and these written registers were transmitted every week to the Royal Observatory.

I have been favoured by Mr. Ellis, who, at my request, has kindly superintended the preparation of the results of observations of thermometers in the water of the Thames, with the following remarks on the nature of the observations and the elements for their reduction.

"The thermometers were inclosed in an upright wooden trunk attached to the side of the ship, its lower portion projecting into the water; the trunk was closed at the bottom; the closing plate, and that portion of the sides which was under water, being perforated with holes, to allow the water easily to flow through. The thermometers were suspended in the trunk, so as to be about two feet below the surface of the water, and one foot above the bottom of the trunk.

"The instruments employed throughout were, one for highest temperature, and one for lowest temperature. For highest temperature two constructions have been successively used: the earlier, in which the mercury, with rising temperature, pushes up a steel index, leaving it detached when the temperature falls; the later, in which the column of mercury becomes divided on fall of temperature, the principal portion of the column bein $g$ left in the tube. For lowest temperature, a spirit thermometer was employed, its index being contained within the column of spirit. The index-errors of the two thermometers in use were properly determined, and corrections for them were applied when necessary.

"The thermometers were read every morning at 9 a.m.

"The observations of atmospheric temperature at the Royal Observatory were made with the thermometers in ordinary use at the elevation of 4 feet above the ground."

It will be remarked that the indications of the thermometers in the Thames were read only once in each day. I could have wished that a greater number of readings could have been taken, sufficiently numerous to exhibit the dependence of the tempera. ture of the Thames-water upon the phase of the tide. But under the circumstances this was impracticable. To establish a selfregistering apparatus was out of question; and if on a few occasions we had gone through the labour of making observations at every hour of day and night, the conclusions deduced from those few instances might havs been vitiated by accidents. But I am able to assert positively, as a result from the reductions to be exhibited in the following pages, that nothing has been lost from the restriction of the plan of observation. It will be seen that 